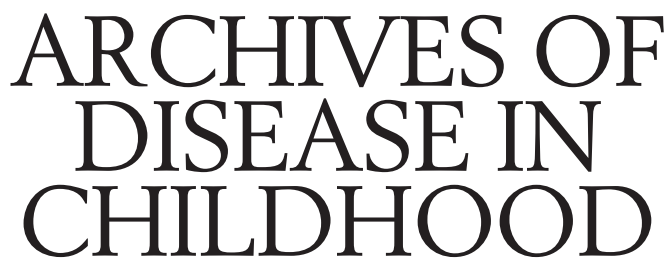

The fournal of the Royal College of Paediatrics and Child Health

\title{
Annotations
}

\section{Neonatal origins of schizophrenia}

Schizophrenia is not an illness which impinges much upon the daily practice of paediatricians or, indeed, child psychiatrists, as only a tiny proportion of diagnosed cases $(<5 \%)$ arise before the age of 16 years. ${ }^{1}$ Schizophrenia is one of the few chronic diseases which arise principally during late adolescence and early adulthood, normally the healthiest period of life. There is increasing evidence, however, that neurodevelopmental factors, acting in utero and in early childhood, are important in determining the risk for later schizophrenia. ${ }^{23}$

\section{Genetic risk}

There is no doubt that genetic factors are involved in the aetiology of schizophrenia. ${ }^{4}$ First degree relatives of patients have a morbid risk of developing schizophrenia which is eight to 10 times higher than the risk in the general population; this risk rises to approximately $50 \%$ in the identical twins of schizophrenics. Now that a neurodevelopmental aetiological model is considered most likely, genes that control early development have come under particular suspicion. Unfortunately, in spite of an intensive effort to locate and identify susceptibility genes for schizophrenia, none has yet been found. ${ }^{5}$

\section{Environmental risk}

The fact that the monozygotic concordance rate for schizophrenia is only $50 \%$ indicates that environmental factors must also be involved, and simple additive models suggest that between $20-30 \%$ of the variance in liability to schizophrenia may be attributable to non-genetic factors. What are these environmental factors and how might they operate?

\section{PERINATAL COMPLICATIONS}

Schizophrenic patients, as a group, experience a greater number of birth complications than controls. ${ }^{6}{ }^{7}$ Inspection of the particular complications associated with schizophrenia suggests that hypoxic-ischaemic brain damage may be the common mechanism. ${ }^{8}$ Schizophrenics who have suffered perinatal complications are especially likely to show lateral ventricular damage and decreased volume of the hippocampus. ${ }^{9}$ Recent findings from a 28 year follow up of a Finnish birth cohort have shown that children with perinatal brain damage (defined as neonatal convulsions, low Apgar scores, asphyxia, intraventricular haemorrhage, or abnormal neurological signs in the newborn period) were seven times more likely to develop schizophrenia in adulthood than the remainder of the cohort. ${ }^{10}$ These results indicate that almost $7 \%$ of schizophrenia in the general population might be attributable to this factor. Labour and delivery complications are relatively common in the general population, however, and only rarely are associated with schizophrenia. Therefore, for schizophrenia to result, either a particular neuronal system must be damaged or the individual must carry genetic vulnerability.

FETAL MALDEVELOPMENT

A number of studies have shown that schizophrenics are more likely to have had low birth weight and decreased head circumference at birth. ${ }^{11}$ Minor physical abnormalities and dermatoglyphic abnormalities, which are thought to represent "fossilised" evidence of early developmental deviance, also occur to excess in schizophrenia, ${ }^{12}$ as do cortical cytoarchitectural changes which are consistent with disturbances of development during gestation. ${ }^{13}$ These indicators of fetal maldevelopment may indicate environmental insult to the fetus. A study of monozygotic twins discordant for schizophrenia has shown that the affected cotwin had more markers of prenatal developmental disruption than the unaffected twin, ${ }^{14}$ and a comparison of familial and non-familial schizophrenics showed that minor physical anomalies were more likely to occur in the latter. ${ }^{15}$ Complications of pregnancy which have been associated with schizophrenia include prenatal exposure to influenza, ${ }^{16}$ prenatal nutritional deprivation, ${ }^{17}$ and rhesus incompatibility. ${ }^{18}$ The mechanism of action of these effects is not yet elucidated and effect sizes are small. The association with influenza may reflect a neurotoxic effect of influenza on the fetal brain, or an effect related to maternal immunological responses to infection. The association with rhesus incompatibility may be mediated through fetal hypoxia resulting from haemolysis.

\section{CHILDHOOD CENTRAL NERVOUS SYSTEM INFECTIONS AND} EPILEPSY

Data from the same Finnish cohort as discussed above, showed that individuals who had suffered a viral central nervous system infection during childhood were almost five times more likely to develop schizophrenia than the comparison group. ${ }^{19}$ The incidence of schizophrenia was particularly high, at $12.5 \%$, among a group of 16 individuals who had contracted neonatal coxsackie $\mathrm{B}$ meningitis during an epidemic in one maternity unit. The incidence among the rest of the study population was $0.7 \%$. Patients with schizophrenia in this series were also two to three times more likely to have a history of childhood epilepsy than the rest of the study population. 
CHILDHOOD DEVELOPMENTAL ABNORMALITIES

High risk studies

Developmental abnormalities during different stages of childhood have been found in $25-50 \%$ of children born to schizophrenic mothers ("high risk" children). ${ }^{2021}$

These include: (1) hypoactivity, hypotonia, and poor "cuddliness" during the neonatal period; (2) a disordered pattern of acquisition of milestones in infancy; (3) "soft" neurological signs, in particular poor motor coordination in early childhood; and (4) deficits in attention and information processing in late childhood.

These findings indicate that at least part of the genetic vulnerability to schizophrenia is manifest through abnormal neurodevelopment. Follow up will continue on these high risk samples to determine whether the children who have displayed such neurodevelopmental abnormalities will go on to develop schizophrenia.

\section{General population birth cohort studies}

Similar findings have been reported among the 1946 British birth cohort. This cohort of 4746 British children, who were born in one week in March 1946, has been studied on over 20 occasions up to the age of 43 years. The 30 children who went on to develop schizophrenia as adults could be distinguished from their peers in these ways ${ }^{22}$ :

- Motor developmental milestones, in particular walking, were delayed by an average of 1.2 months

- More speech problems (odds ratio (OR) 2.8)

- Lower educational test scores at ages 8,11 , and 15

- Preference for solitary play at ages 4 and 6 years (OR 2.1).

Home movies'studies

A unique collection of "home movies" depicting schizophrenic patients during childhood shows that the preschizophrenic children can be distinguished from their siblings, with a high degree of accuracy, by the presence of subtle abnormalities of motor tone and facial expression. ${ }^{23}$ Retrospective studies have shown that preschizophrenic children have markedly poorer overall social adjustment in childhood than normal controls or children destined to develop affective psychosis. ${ }^{24}$

\section{Gene-environment interaction}

Although having an affected relative remains the strongest risk factor for schizophrenia (table 1), there are many prenatal and postnatal risk factors with smaller effect sizes which cannot be ignored. These environmental risk factors may act additively with each other or may indicate the existence of gene environment interactions. ${ }^{25}$ Birth complications or adverse psychosocial circumstances in childhood may interact with genetic vulnerability to increase the risk

Table 1 "Best estimate" effect sizes of various genetic and environmental risk factors for schizophrenia (expressed as odds ratios or relative risks)

\begin{tabular}{lll}
\hline Category of risk factor & Specific risk factors & $\begin{array}{l}\text { Best estimate } \\
\text { of effect size }\end{array}$ \\
\hline Genetic $^{\star}$ & $\begin{array}{l}\text { Monozygotic twin of schizophrenic } \\
\text { patients }\end{array}$ & 46 \\
& $\begin{array}{l}\text { Dizygotic twin of schizophrenic patient } \\
\text { Child/sibling of schizophrenic patient }\end{array}$ & 14 \\
Childhood & 10 \\
developmental $\dagger$ & Delayed milestones & 3 \\
Prenatal and postnatal & Speech problems & 3 \\
environment $\dagger$ & Pre-eclampsia & 9 \\
& Perinatal brain damage & 7 \\
& Rhesus incompatibility & 3 \\
& "Unwanted" pregnancy & 2 \\
& Severe undernutrition (1st trimester) & 2 \\
& Maternal influenza (2nd trimester) & 2
\end{tabular}

${ }^{\star}$ Relative risks; † odds ratios.

\section{Key messages}

- Most schizophrenics have subtle brain abnormalities of developmental origin, and many show impairments of motor, cognitive, and social function in childhood, decades before the onset of frank psychosis. These findings have led to the conclusion that schizophrenia is a neurodevelopmental disorder

- The strongest risk factor for schizophrenia is having an affected relative. Prenatal and perinatal risk factors, in particular prenatal viral exposure and fetal hypoxia, also appear to be important

- An important clinical implication of the existence of prenatal and neonatal risk factors is that some forms of schizophrenia may be preventable

of psychosis. ${ }^{26}$ For example, there is a greater risk of schizophrenia among genetically vulnerable children who were placed in poorly functioning adoptive homes compared with those placed in well functioning homes, ${ }^{27}$ and high risk children reared in a kibbutz had increased rates of schizophrenia compared with those who were reared in family homes. ${ }^{28}$ In other words, the pathogenic effects of adverse social circumstances appears to increase risk of schizophrenia only in children who have some degree of genetic vulnerability.

\section{Conclusion}

An important clinical implication of the prenatal and neonatal risk factors mentioned in this paper is that some forms of schizophrenia may be preventable. Environmental agents can be more easily manipulated than genetic factors. Avoidance of perinatal hypoxia, nutritional supplemention during pregnancy, and prevention of central nervous system infection in childhood, particularly neonatal coxsackie $B$ infection, may help reduce the incidence of schizophrenia. We are still a long way, however, from testing the efficacy of such measures, or indeed from developing an accurate screening test for schizophrenia. Although children destined to develop schizophrenia in adulthood have been shown to differ from their peers in social and intellectual function, these behavioural and cognitive risk factors are non-specific and cannot be applied to the general population. Close observation of children who are genetically vulnerable to schizophrenia, may prove useful in this regard. Measures such as careful supervision of adoptive or foster home placements, social skills training, protection from stressors, and early referral to psychiatric services could help prevent psychotic breakdown among high risk children. Although definitive evidence for such measures is lacking, early treatment of psychosis has been shown to improve prognosis, ${ }^{29}$ and studies of prevention in schizophrenia are already underway. In conclusion therefore, study of the neonatal and childhood precursors of schizophrenia allow the possibility of prevention and early intervention in at least some cases of the disorder. Although this research is in its early stages, it may not be necessary to wait until the gene or genes for schizophrenia are discovered to begin reorienting our approach to this devastating illness.

MARY CANNON ROBIN M MURRAY

Department of Psychological Medicine, Institute of Psychiatry,

De Crespigny Park,

Denmark Hill,

London SE5 8 AF

Mary Cannon was supported by a Wellcome Trust research training fellowship in clinical epidemiology. 
1 Asarnow RF, Asarnow JR. Childhood onset schizophrenia. Schizophr Bull 1994;20:591-7.

2 Cannon M, Jones P. Schizophrenia: neuroepidemiology review series. F Neurol Neurosurg Psychiatry 1996;61:604-13.

3 Murray R, Lewis S. Is schizophrenia a neurodevelopmental disorder? BMf $1987 ; 295: 681-2$

4 Sham P. Genetic epidemiology. Br Med Bull 1996;52:408-33.

5 Kidd KK. Can we find genes for schizophrenia? Am $\mathscr{f}$ Med Genet (Neuropsychiatric Genetics) 1997;74:104-11.

6 Lewis SW, Owen MJ, Murray RM. Obstetric complications and schizophrenia: methodology and mechanisms. In: Schultz SC, Tamminga CA, eds. Schizophrenia: a scientific focus. New York: Oxford University Press, 1989:56-9.

7 Geddes JR, Verdoux H, Takei N, et al. Individual patient data meta-analysis of the association between schizophrenia and abnormalities of pregnancy and labour. Schizophr Res 1997;24:161.

8 Kendell RE, Juszczak E, Cole SK. Obstetric complications and schizophrenia: a case-control study based on standardised obstetric records. Br F Psychiatry 1996;168:556-61.

9 Stefanis N, Yakeley J, Frangou S, et al. Pregnancy and birth complications (PBC) - associated hippocampal volume reduction in sporadic schizophrenia. Schizophr Res 1997;24:157-8.

10 Jones P, Rantakallio P, Hartikainen A-L, et al. Schizophrenia as a long-term outcome of pregnancy, delivery and perinatal complications: a 28-year follow-up of the 1966 North Finland general population birth cohort. Am $f$ Psychiatry (in press)

11 McGrath JJ, Murray RM. Risk factors for schizophrenia-from conception to birth. In: Hirsch S, Weinberger D, eds. Schizophrenia. Oxford: Blackwell, 1995:187-205.

12 Jones P, Murray R. The genetics of schizophrenia is the genetics of neurodevelopment. Br f Psychiatry 1991;158:615-23.

13 Weinberger DR. Schizophrenia:from neuropathology to neurodevelopment. Lancet 1995;346:552-7.

14 Bracha HS, Torrey EF, Gottesman II, et al. Second-trimester markers of fetal size in schizophrenia: a study of monozygotic twins. Am f Psychiatry 1992;149:1355-61.

15 Griffiths TD, Sigmundsson T, Takei N, et al. Minor physical anomalies in familial and sporadic schizophrenia - the Maudsley family study. $\mathcal{F}$ Neurol Neurosurg Psychiatry (in press).
16 O'Callaghan E, Sham P, Takei N, et al. Schizophrenia after prenatal exposure to the 1957 A2 influenza epidemic. Lancet 1991;337:1248-50.

17 Susser E, Lin P. Schizophrenia after prenatal exposure to the Dutch hunger winter of 1944-1945. Arch Gen Psychiatry 1992;49:983-8.

18 Hollister JM, Laing P, Mednick SA. Rhesus incompatibility as a risk factor for schizophrenia in male adults. Arch Gen Psychiatry 1996;53:19-24.

19 Rantakallio P, Jones P, Moring J, et al. Association between central nervous system infections during childhood and adult onset schizophrenia and other psychoses: a 28-year follow-up. Int f Epidemiol 1997;26:837-43.

20 Marcus J, Hans SL, Auerbach JG, et al. Children at risk for schizophrenia: the Jerusalem infant development study. Arch Gen Psychiatry 1993;50:797809 .

21 Fish B. Infants at risk for schizophrenia: sequelae of a genetic neurointegrative defect. Arch Gen Psychiatry 1992;49:221-35.

22 Jones P, Rodgers B, Murray R, et al. Childhood developmental risk factors for schizophrenia in the 1946 national birth cohort. Lancet 1994;344:1398 402

23 Walker E, Lewine RJ. Prediction of adult-onset schizophrenia from childhood home movies of the patients. Am f Psychiatry 1994;147:1052-6.

24 Cannon M, Jones P, Gilvarry K, et al. Premorbid social adjustment in schizophrenia and bipolar disorder: similarities and differences. Am $\mathcal{F}$ Psychiatry 1997;154:1544-50.

25 Kendler KS. Genetic epidemiology in psychiatry: taking both genes and environment seriously. Arch Gen Psychiatry 1995;52:895-9.

26 Cannon TD, Mednick SA, Parnas J, et al. Developmental brain abnormalities in the offspring of schizophrenic mothers. 1: Contributions of genetic and environmental factors. Arch Gen Psychiatry 1993;50:551-64.

27 Tienari P. Interaction between genetic vulnerability and family environment: the Finnish adoptive study of schizophrenia. Acta Psychiatr Scand 1991;84:460-5.

28 Mirsky AF, Silberman EK, Latz A, et al. Adult outcomes of high-risk children: differential effects of town and kibbutz rearing. Schizophr Bull 1985;11:150-6.

29 Johnstone EC, Crow TJ, Johnson AL, et al. The Northwick Park study of first episode schizophrenia. 1. Presentation of the illness and problems relating to admission. Br f Psychiatry 1986; 148:115-20.

\section{Benign childhood occipital seizures}

Benign childhood epilepsy with centrotemporal spikes or rolandic epilepsy is well recognised, ${ }^{1-3}$ but benign childhood occipital seizures (BCOS) are not widely known. ${ }^{1-7}$

BCOS have a prevalence of $20-25 \%$ among benign childhood partial seizures, ${ }^{6}$ with two clinical forms: early onset BCOS described by Panayiotopoulos ${ }^{4} 6$ and late onset BCOS of Gastaut. ${ }^{5}$ Idiopathic photosensitive occipital seizures are also well documented. ${ }^{8-10}$

\section{Early onset benign childhood occipital seizures}

Seizures consist of autonomic and behavioural disturbances with vomiting and deviation of the eyes lasting from minutes to hours. They are mainly nocturnal and often progress to convulsions. Consciousness is usually impaired from onset or during the ictus. By definition, seizures lasting for more than half an hour are status epilepticus. In one third of these children, the phase of deviation of the eyes with vomiting and impairment of consciousness is prolonged for more than 30 minutes (partial status epilepticus) and usually ends with generalised convulsions. A typical case is of a child who wakes up from sleep agitated, vomiting, eyes deviated to one side, and who may or may not be able to communicate for minutes to hours before hemiconvulsions or generalised convulsions begin. Onset is between 1-12 years, peak is at 5 years, and remission occurs within 1-2 years from onset. In one third of the patients, seizures or even partial status epilepticus are single events in the child's life. The mean total of seizures is three and the maximum is $15 .^{7}$ Early onset BCOS are entirely benign. Only four out of 113 children with early onset BCOS developed rolandic seizures, and only one continued with infrequent generalised convulsions. ${ }^{7} \mathrm{~A}$ grave neurological condition may be suspected during the prolonged ictus but the normal state after ictal should be reassuring.
The electroencephalogram manifestations are severe with long runs of high amplitude occipital sharp and slow waves. They often appear when the eyes are closed because they are activated by the elimination of fixation and central vision (fixation-off sensitivity). ${ }^{4}{ }^{7}$ Spikes in the centrotemporal or other locations occur in $10-30 \%$ of patients. ${ }^{67}$ There is no photosensitivity. Occipital spikes should raise the possibility of BCOS, but they may also occur in children who do not suffer from seizures and in those with severe symptomatic epilepsies. ${ }^{6}$ Furthermore, $10 \%$ of children with early onset BCOS may have a normal interictal electroencephalogram. ${ }^{67}$

\section{Late onset benign childhood occipital seizures}

Seizures manifest with visual hallucinations and/or blindness, they are frequent, mainly diurnal lasting from seconds to less than three minutes. They may progress to other seizure manifestations, mainly hemiconvulsions. Loss of consciousness may occur with or without convulsions. A postictal headache occurs in $30 \%$ of patients. Mean age at onset is $7-8$ years, and prognosis is usually good with remission often occurring within two to three years.

The electroencephalogram is identical to that of the early onset BCOS with occipital paroxysms when the eyes are closed. ${ }^{1-7}$

The differential diagnosis of late onset BCOS from basilar migraine or migraine with aura has been recently detailed. ${ }^{11}$ The main cause of misdiagnosis is that visual hallucinations are often not evaluated quantitatively and qualitatively. ${ }^{11}$ Instead, they are erroneously abbreviated in terms such as fortification spectra, teichopsia, scintillating scotomata, phosphenes, and their variations, whose meaning often misrepresents the actual descriptions of the patients.

In epileptic seizures, elementary visual hallucinations are frequent, nearly daily, and short - they usually last from a 
few seconds to less than three minutes. They consist of predominantly multicoloured circular patterns, "hundreds of brilliant small balls of many colours". Onset is always on the same side. These visual fits may progress to other motor partial seizures, loss of consciousness, and convulsions. Postictal headache is rarely throbbing and severe. Interictal electroencephalogram occipital spikes usually reveals their epileptic nature.

In migraine with aura, visual hallucinations are prolonged, developing over more than three minutes and lasting for 20-30 minutes. They are not as frequent as those in BCOS. They are characterised by predominantly black and white linear and zigzag patterns. Colours may be described, but they are usually not predominant and occur in the periphery of the visual hallucinations along with the zigzag bright streaks or flashes of light. Side alteration between attacks is frequent. Photophobia and irritation are common. Throbbing headache and vomiting follow.

In basilar migraine, bilateral visual hallucinations similar to those of migraine with aura or blindness are associated with brain stem symptoms of vertigo, ataxia, tinnitus, and peripheral dysaesthesias. These are followed by severe, throbbing, posterior, bilateral headache occurs. Impairment of consciousness may occur in a quarter of the cases, usually between the aura and the headache. It is usually brief, from one to 10 minutes, with features distinguished from epileptic seizures. It is slow in onset, never abrupt, and never causes the patient to fall or to be injured. Prolonged and severe impairment of consciousness are rare. In between these attacks classical migrainous episodes with aura may occur. The interictal electroencephalogram is usually normal, but slow wave abnormalities are seen during the attacks.

\section{Idiopathic photosensitive occipital seizures}

Reflex epilepsies are classified as "epilepsies characterised by seizures with specific modes of precipitation". ${ }^{10}$ Idiopathic occipital seizures induced by television, video games, and intermittent photic stimulation are well documented. ${ }^{8-10}$ Onset is between $5-17$ years. ${ }^{9}$ Seizures are photically triggered and manifest with multicoloured circular visual hallucinations often associated with blindness. Tonic deviation of the eyes, epigastric discomfort and vomiting, headache, and generalised convulsions may follow. ${ }^{9}$ Duration varies from two to five minutes or up to two hours. Prognosis is uncertain; some children may have only one or two seizures, but others may not remit. ${ }^{9}$ An interictal electroencephalogram shows spontaneous and photically induced occipital spikes. Centrotemporal spikes may coexist. Ictal electroencephalograms document the occipital origin and spreading of discharges to the temporal regions. ${ }^{9}$

Unified concept of benign childhood partial seizures Benign childhood partial epilepsies, classified among the "age and localisation related idiopathic epilepsies" ${ }^{1-3}$ may be unified as they share common clinical and electroencephalographic characteristics and one may evolve into another. ${ }^{237}$ Seizures are infrequent or solitary, usually nocturnal, and decrease within one to three years from onset. Ictal hypersalivation, vomiting, headache, pallor, or sweating, unusual in other epileptic syndromes, are frequent and may occasionally appear in isolation. Despite normal development, normal brain imaging, and rarity of seizures, the abnormalities on the electroencephalogram are severe and exaggerated by drowsiness and sleep. Similar features on the electroencephalogram, resolving with age, are found in $1-2 \%$ of asymptomatic children of school age.

\section{Epilepsy or seizures?}

The term epilepsy, even in its strict definition of at least two unprovoked seizures, is not appropriate for $30 \%$ of the children with early onset BCOS who have only one fit. ${ }^{6}{ }^{7} \mathrm{I}$ consider that the other $70 \%$ of these children should not be discriminated and labelled with "epilepsy" just because they have two or more seizures. Preferable terms are benign childhood partial seizures or benign childhood seizure susceptibility syndromes, ${ }^{2}$ denoting an idiopathic liability to seizures and/or electroencephalography manifestations which are age specific. The risk of recurrent seizures in adult life is less $(1-2 \%)$ than in febrile convulsions $(4 \%){ }^{2}$

\section{Treatment}

The conclusion from a recent study on early onset BCOS is that "treatment may not be warranted". ${ }^{7}$ This is certainly the case for the $30 \%$ who have only one seizure in their life. The remaining $70 \%$, with an average of three seizures, also may not need medication. ${ }^{12}$ If treatment is considered necessary, carbamazepine, sodium valproate, and phenobarbitone are equally effective. ${ }^{7}$ Carbamazepine is preferred because of fewer side effects. It is important to remember that remission occurs within one to two years after the first seizure, and antiepileptic medication should be withdrawn after this period.

When early onset, BCOS presents with partial status epilepticus which may be prolonged for hours and terminate with generalised convulsions. ${ }^{67}$ This needs urgent treatment with intravenous diazepam. Rectal diazepam should be prescribed for recurrent partial status epilepticus as for febrile convulsions.

In late onset BCOS, seizures may be very frequent, often daily. They usually respond well to carbamazepine which may be needed for two to four years. ${ }^{11}$

In photosensitive occipital seizures, avoidance of precipitating factors may be sufficient, ${ }^{8-10}$ but if seizures persist, long term medication with sodium valproate may be necessary. $^{9}{ }^{10}$

C P PANAYIOTOPOULOS

Department of Clinical Neurophysiology and Epilepsies,

St Thomas' Hospital,

London SE1 7EH

1 Commission on Classification and Terminology of the International League against Epilepsy. Proposal for revised classification of epilepsies and epileptic syndromes. Epilepsia 1989;30:389-9.

2 Panayiotopoulos CP. Benign childhood partial epilepsies: benign childhood seizure susceptibility syndromes. F Neurol Neurosurg Psychiatry 1993;56:2-

3 Watanabe K. Benign partial epilepsies. In: Wallace S, ed. Epilepsy in children. London: Chapman and Hall, 1996:293-313.

4 Panayiotopoulos CP. Inhibitory effect of central vision on occipital lobe seizures. Neurology 1981;31:1331-3.

5 Gastaut H. A new type of epilepsy: benign partial epilepsy of childhood with occipital spike-waves. Clin Electroencephalogr 1982;13:13-22.

6 Panayiotopoulos CP. Benign childhood epilepsy with occipital paroxysms. In: Andermann F, Beaumanoir A, Mira L, Tassinari CA, eds. Occipital seizures and epilepsies in children. London: John Libbey, 1993:151-64.

7 Ferrie CD, Beaumanoir A, Guerrini R, et al. Early-onset benign occipital seizure susceptibility syndrome. Epilepsia 1997;38:285-93.

8 Ferrie CD, De Marco P, Grunewald S, et al. Video game induced seizures. $\mathcal{F}$ Neurol Neurosurg Psychiatry 1994;57:925-31.

9 Guerrini R, Dravet C, Genton P, et al. Idiopathic photosensitive occipital lobe epilepsy. Epilepsia 1995;36:883-91.

10 Panayiotopoulos CP. Epilepsies characterised by seizures with specific modes of precipitation (reflex epilepsies). In: Wallace S, ed. Epilepsy in children. London: Chapman and Hall, 1996:355-75.

11 Panayiotopoulos CP, Ahmed Sharoqi I, Agathonikou A. Occipital seizures imitating migraine aura. $\mathcal{F} R$ Soc Med 1997;90:255-7.

12 Camfield C, Camfield P, Gordon K, et al. Does the number of seizures before treatment influence ease of control or remission of childhood epilepsy? Neurology 1996;46:41-4. 


\section{Gastrointestinal problems in the immunosuppressed patient}

The gastrointestinal tract is a major component of the human immune system with a total lymphoid mass which is comparable with bone marrow. ${ }^{1}$ The Peyer's patches are the principal sites of interaction among luminal antigens and lymphocytes, while the scattered lymphocytes in the lamina propria and epithelium are the effector cells that mediate immune response. ${ }^{2}$ The gut is also a site of synthesis and release of a specialised form of immunoglobulin A (secretory $\operatorname{IgA}$ ) which is resistant to digestion. These immunological mechanisms are important because the gut has a huge surface area which interacts with the numerous potentially noxious agents including micro-organisms and dietary antigens. ${ }^{23}$ The intestinal tract is also one of the most metabolically active tissues in the body, with mucosal renewal taking place every three to five days, it is not surprising therefore that the gut is often the target organ for pathological processes in the immunosuppressed patients. ${ }^{45}$ The deleterious effects of immunosuppression on the integral functioning of the gut are assuming greater importance now that the use of potent long term immunosuppression has become widespread, for example in autoimmune diseases and organ transplantation.

\section{Pathophysiology of immunosuppression on gastrointestinal function}

The effects of immunosuppression on the gastrointestinal tract are multiple and include loss of gastric acidity, impaired immune response, reduced mucosal integrity, and compromised mucosal regeneration.

THE SUPPRESSION OF GASTRIC ACID SECRETION

This may be induced by treatment with $\mathrm{H}_{2}$ blockers or be secondary to malnutrition or immaturity (as in neonates), and the number of viable organisms surviving passage through the stomach can therefore increase by a 1000 -fold causing gastroenteritis.

\section{THE IMMUNE RESPONSE}

The immune response may be globally attenuated by drugs such as steroids (reduction in chemotaxis and kinin production), or more specifically by cyclosporin A and tacrolimus, which inhibit $\mathrm{T}$ lymphocyte proliferation by inhibiting expression of interleukin $2{ }^{6}$ Such immunosuppression may cause persistence of normally mild infections such as cytomegalovirus or cryptosporidium, and permit an increase in commensal organisms. Epstein-Barr virus which infects B lymphocytes can induce B cell proliferation and ultimately B cell lymphoma in the presence of altered immune response. ${ }^{7}$ In transplantation, intestinal graftversus-host disease (GVHD) is a risk when the mass of donor lymphocytes received is comparable with that of the recipient's, as is the case in allogenic bone marrow transplantation or even small bowel transplantation. This risk is increased when the immune system is further suppressed with potent treatments such as OKT3 and antithymocyte globulin.

\section{MUCOSAL INJURY}

Mucosal injury is well documented in patients with chronic intestinal inflammatory states. Loss of intestinal integrity is a recognised sign of rejection in small bowel transplantation. ${ }^{8}$ Mucosal damage (mucositis) frequently occurs after tumour chemotherapy and after conditioning treatment before allogenic bone marrow transplantation in adults, but probably occurs less commonly in children. ${ }^{4}$ Radiation has been shown to cause inflammatory changes in the lamina propria in human adults. ${ }^{9}$ A protein losing enteropathy was reported to occur in up to $90 \%$ of paediatric bone marrow transplants, ${ }^{4}$ and this is associated with hypoalbuminaemia which may contribute to impaired regeneration of the villi.

\section{Aetiologies of intestinal dysfunction}

INFECTIONS

The gastrointestinal tract is a portal of entry for numerous pathogens, and infections are a major cause of morbidity and mortality in immunosuppressed patients. Common viral agents include rotavirus, cytomegalovirus, adenovirus, and coxsackie A virus, ${ }^{4}$ all of which may cause devastating diarrhoea in these patients. Bacterial infections include Campylobacter jejuni and salmonella, ${ }^{3-5}$ which are normally sensitive to gastric acid, and so are a particular risk in patients receiving $\mathrm{H}_{2}$ blockers. ${ }^{10}$ Clostridium difficile infection, which is associated with the use of broad spectrum antibiotics as is common in immunosuppressed patients, may sometimes lead to pseudomembranous colitis. Fungal infections are extremely common ranging from superficial candidiasis to severe systemic infections with candida or aspergillosis involving the intestine and closely related organs such as the liver and spleen. ${ }^{11}$ Infection by protozoa may also be a problem, and Pneumocystis carinii and cryptosporidium are the most frequently identified commensal organisms. ${ }^{5}$ Strongyloides stercoralis is a nematode which may cause a fulminating infection in immunosuppressed patients from the tropical countries. ${ }^{11}$

\section{DRUG TOXICITY}

Immunosuppressive drugs can cause a variety of gastrointestinal lesions including mucosal erosions, bleeding, and viscous perforation (for example, steroids); hepatitis, cholestasis, and pancreatitis (for example, azathioprine); impaired enterocyte function causing malabsorption (for example, mycophenolate and tacrolimus). ${ }^{12}$ Cytotoxic drugs (for example, cyclophosphamide and busulphan), and irradiation used as primary or adjunctive treatments with immunosuppressive agents cause an enteritis associated with gut mucosal ulceration and bleeding. Idarubicin has been associated with more diarrhoea than cyclophosphamide after allogenic bone marrow transplantation, necessitating support with parenteral nutrition. ${ }^{4}$ The use of isolated parenteral nutrition itself, however, may worsen gastrointestinal function because enteral feeding is an important stimulus to pancreatic function, villus growth, and mucosal integrity. ${ }^{13} 14$

IMMUNOLOGICAL REACTIONS

GVHD may cause inflammation in the gut stroma and degeneration and necrosis of crypt cells in which apoptotic bodies are characteristically seen. A severe form of diarrhoea, often containing blood and albumin, may ensue. ${ }^{15}$ Acute GVHD is a systemic disorder typically involving skin and liver in addition to the gastrointestinal tract; other organs such as the lungs and pancreas may also be involved. It usually occurs seven to 50 days after bone marrow transplantation (and occasionally after liver or small bowel transplantation). The damage GVHD causes to the liver is focused in the portal tracts with loss of bile 
ducts and cholestasis, while the parenchyma is relatively spared. Lymphoproliferative disease that develops after transplantation may be considered as an "opportunistic cancer" in which the immunodeficiency state of the host has a key role in fostering the environment necessary for abnormal lymphoproliferation. ${ }^{16}$ The development of lymphoproliferative disease after transplantation (usually leading to undifferentiated $\mathrm{B}$ cell lymphoma) may be related to exposure to Epstein-Barr virus, chronic antigenic stimulation from the allograft, or a direct oncogenic effect of immunosuppression. ${ }^{7}{ }^{17}$ After a heart transplant, approximately $10 \%$ of patients develop lymphoproliferative disease, and $10-15 \%$ of small bowel transplant recipients may develop this disease also. The gut is a common site for the lymphoma to occur and may cause symptoms of obstruction, perforation, bleeding, and diarrhoea as well as chronic anaemia.

\section{VENO-OCCLUSIVE DISEASE}

The peripheral branches of the hepatic veins are susceptible to occlusion by microthrombi, especially after bone marrow transplantation. The mortality rate is up to $30 \%$, with a higher risk for patients who have a history of pretransplant viral hepatitis, radiotherapy, and busulphan conditioning. The increased hepatic venous pressure produces a Budd-Chiari like syndrome with unexpected weight gain and ascites. ${ }^{18}$

\section{Patterns of gastrointestinal disorders}

FEED INTOLERANCE

Feed intolerance is common in immunosuppressed patients and is usually manifested by vomiting and diarrhoea, which may contain frank blood. These symptoms may be related to infections such as bacterial overgrowth and to mucosal inflammation, GVHD, or enterocyte dysfunction. The presentation of infectious diarrhoea may be atypical in that an agent which usually produces superficial lesions in the mucosa may mimic another disorder such as Crohn's disease. ${ }^{19}$ Mucositis induced by chemotherapy and total body irradiation is common in allogenic bone marrow transplantation, and up to half the transplant recipients in one paediatric study required two to four weeks of parenteral nutrition. ${ }^{4}$ Intestinal GVHD occurs in 30-70\% allogenic bone marrow transplant recipients and may provoke a severe diarrhoea. ${ }^{20}$

\section{SECRETORY DIARRHOEA}

This takes the form of a watery stool containing $>60$ $\mathrm{mmol} / \mathrm{l}$ of sodium and may occur in isolation as a result of GVHD, cytomegalovirus, or rotavirus. In patients with chronic immune suppression, secondary to human immunodeficiency virus octreotide has been tried to control the secretory diarrhoea. ${ }^{21}$ A secretory state may also develop after small bowel transplantation.

\section{ABDOMINAL PAIN}

Abdominal pain may occur in severe GVHD, but other causes such as gastritis, typhlitis, or paralytic ileus are more common. Veno-occlusive disease causes a tender hepatomegaly. ${ }^{15} 18$

\section{JAUNDICE}

Jaundice may be secondary to GVHD, veno-occlusive disease, sepsis (especially fungal), viral hepatitis such as cytomegalovirus, lymphoproliferative disease, or biliary sludge, which is common in patients who are receiving parenteral nutrition because of feed intolerance.
MALABSORPTION

Malabsorption is manifested by copious watery diarrhoea in which stools test positive for reducing substances and may contain fat if cholestasis or pancreatic dysfunction is present. Villus atrophy and mucositis result in a reduction in absorptive surface and marked carbohydrate malabsorption. $^{22}$

BLEEDING

Bleeding presenting as haematemesis, melaena, and rectal bleeding is common after major surgery and bone marrow transplantation..$^{23}$ It may be related to the direct mucosal damaging effects of the drugs (steroids), poor anastomotic healing, anastomotic ulceration, or to haemorrhagic colitis/enteritis related to the infectious agents (for example, cytomegalovirus). Impaired platelet function and prolonged clotting times may also contribute to intestinal bleeding.

PERFORATION AND OBSTRUCTION

Perforation or obstruction, or both, are uncommon but may occur after cytomegalovirus enteritis, or steroid induced peptic ulceration. Silent perforation may sometimes occur in some of the patients (especially those with previous abdominal surgeries or underlying pathologies such as duodenal ulcers) who are receiving high dose corticosteroids, especially in the immediate period after the transplant. ${ }^{24}$ Transmural lymphoproliferative disease may perforate or obstruct the intestinal lumen.

\section{Diagnosis}

The patterns of symptoms and signs vary in severity, and overlap despite different aetiologies, so investigation is crucial in order to make a specific diagnosis. The most useful tests screen for infection, malabsorption, and histological evidence of tissue damage mediated either by the immune system, chemotherapy, or infectious agents.

\section{First line screening investigations}

STOOL CULTURE AND ELECTRON MICROSCOPY

These processes can identify up to three quarters of the infectious agents. ${ }^{50}$ Semiquantitative polymerase chain reaction (PCR) on circulating white cells reliably identifies cytomegalovirus infection and is soon likely to be applied to other tissues for other antigens (Epstein-Barr virus, for example).

\section{FAECAL STEATOCRIT}

Faecal steatocrit (greater than $2 \%$ fat in a $2 \mathrm{ml}$ stool sample), ${ }^{25}$ faecal chymotrypsin (a marker of pancreatic enzyme function), and faecal reducing substances all suggest malabsorption. Protein malabsorption suggests a submucosal injury is present (for example, GVHD) and was shown to be present in $47 \%$ of children after bone marrow transplantation in a study by Papadopoulou et $a .^{4} \mathrm{~A}$ protein losing enteropathy also occurs when the portal pressure is raised as in veno-occlusive disease. A faecal $\alpha_{1}$-antitrypsin of more than $2.2 \mathrm{mg} / \mathrm{g}$ of stool is indicative of a protein losing enteropathy. ${ }^{4}$

\section{ENDOSCOPY}

Endoscopy provides direct visualisation for biopsy of mucosal lesions and can localise the site of blood loss. Light microscopic examination of the tissue biopsy specimens can provide conclusive evidence for GVHD, lymphoproliferative disease, cytomegalovirus, villous atrophy, inflammation, and rejection (in the case of small bowel transplant). ${ }^{26}$ 
RADIOLOGY

Radiology, including plain abdominal $x$ ray and abdominal ultrasound, can detect obstruction and perforation, anastomotic leak, toxic megacolon, features of acute pancreatitis, mucosal oedema, ascites or fluid collections, and visceral candidiasis. ${ }^{27}$

\section{Second line investigations}

ABNORMAL LIVER FUNCTION

When abnormal liver function tests develop, is extremely useful to take a biopsy specimen from the liver for identifying microabscesses, GVHD, veno-occlusive disease, and drug toxicity. The risks of bleeding, however, are high in allogenic bone marrow transplantation because of marrow aplasia resulting in thrombocytopenia, and the recipients may have coagulopathy from other problems such as sepsis and GVHD. Therefore, blood product support and ultrasound guidance of the biopsy needle is recommended. Transjugular liver biopsy may be a safer option in older children after allogenic bone marrow transplantation, where necessary.

\section{RADIONUCLIDE IMAGING}

Radionuclide imaging using white cell labelling may be helpful in delineating the site of gut inflammation/ abscesses, but steroid administration (leading to impaired neutrophil function) and reduced white cell counts are common in immunosuppressed patients and limit the usefulness of this test. ${ }^{28}$ In brisk gastrointestinal bleeding, technetium-99m labelled red blood cells scan localise the site with diagnostic yield comparable with angiography.

\section{INTESTINAL PERMEABILITY}

Intestinal permeability is increased whenever the tight junctions between enterocytes are impaired by oedema, as in surgery to the intestinal tract, during gastrointestinal infections, after bone marrow transplant, and during acute cellular rejection after small bowel transplantation. ${ }^{29}$ Intestinal permeability can be simply measured by analysing the differential absorption of two non-metabolised carbohydrates, but it is more useful in research than clinical practice.

\section{Management}

The non-specificity of gastrointestinal symptoms and the great diversity of potential pathologies affecting immunosuppressed patients mean that it is essential to make a precise diagnosis. Opportunistic infections or bacterial overgrowth may require specific treatment (for example, ganciclovir for cytomegalovirus, enteral immunoglobulin for adenovirus infection, ${ }^{30}$ metronidazole for bacterial overgrowth, and co-trimoxazole for pneumocystis) and reduction in immune suppression if possible. Granulocyte colony stimulating factor may be helpful in patients with severe neutropenia. In small bowel transplant recipients, infection or altered permeability is a manifestation of graft rejection and, paradoxically, the dose of the immunosuppressants may need to be increased at the same time as instituting broad spectrum antibiotics. Acute GVHD is managed using a combination of high dose corticosteroids and cyclosporin, with antithymocyte or antilymphocyte globulin used as a second line treatment. Azathioprine and thalidomide are useful in the treatment of chronic GVHD. Ursodeoxycholic acid may be valuable if the GVHD is damaging the bile ductules. ${ }^{31}$ The use of irradiated blood is presently considered the most effective method of preventing GVHD after transfusion. ${ }^{32}$ The management of veno-occlusive disease is supportive using diuretics and fluid restriction with thrombolytic agents such as alteplase (tissue type plasminogen activator) for severe and progressive cases. ${ }^{18}$ Gastrointestinal bleeding may occasionally require surgery if medical treatment with $\mathrm{H}_{2}$ blockers, proton pump inhibitors, and sucralfate fails. Nasogastric tube feeding with high energy feed is an important method of improving the nutritional status and gastrointestinal function of immunosuppressed children. ${ }^{4}$

\section{Summary}

Gastrointestinal dysfunction is common in immunosuppressed children. It is almost invariably multifactorial, and often presents a diagnostic dilemma. Systematic investigation should allow an accurate diagnosis to be made so that immunosuppressed children can benefit from effective and timely interventions and may return to normal health more quickly and completely.

We are most grateful to Dr M S Murphy for his critical appraisal of the manuscript.

VYOM AGGARWAL

Department of Gastroenterology and Nutrition,

Institute of Child Health,

University of Birmingham,

Birmingham

M D WILLIAMS

Department of Paediatric Haematology,

Birmingham Children's Hospital NHS Trust,

Birmingham

$S$ V BEATH

The Liver Unit

Birmingham Children's Hospital NHS Trust

Ladywood Middleway, Ladywood,

Birmingham B16 8ET

1 Dobbins WO. Gut immunophysiology: a gastroenterologist's view with emphasis on pathophysiology. Am f Physiol 1982;242:G1-8.

Udall J. Immunologic aspects of gut function. In: Walker WA, Watkins JB, eds. Nutrition in pediatrics; basic science and clinical aspects. Boston: Little, Brown, 1985:301.

3 Webster ADB. Immunodeficiency and gut. Balliere's clinical gastroenterology 1987;1:547-65.

4 Papadopoulou A, Lloyd DR, Williams MD, et al. Gastrointestinal and nutritional sequelae of bone marrow transplantation. Arch Dis Child 1996;75: 208-13.

5 Engelhard D, Marks MI, Good RA. Infections in bone marrow transplant recipients. F Pediatr 1986;108:335-43.

6 Hooks MA. Tacrolimus, a new im

Hooks MA. Tacrolimus, a new immunosupp
literature. Ann Pharmacother 1994;28:501-11.

Sokal EM, Caragiozoglou T, Lamy M, et al. Epstein-Barr virus serology and Epstein-Barr virus-associated lympho-proliferative disorders in pediatric liver transplant recipients. Transplantation 1993;56:1394-8.

8 Teitelbaum DH, Sonnino RE, Harmel RP Jr. Loss of intestinal integrity following small bowel transplant rejection in the rat. Transplant Proc 1996;28: 2547-8

9 Fernandez Banares F, Villa S, Esteve M, et al. Acute effects of abdominopelvic irradiation on the oro-cecal transit time, its relation to clinical symptoms, and bile salt and lactose malabsorption. Am $\mathcal{f}$ Gastroenterol 1991;86:1771-7.

10 Neal KR, Brij SO, Slack RCB, et al. Recent treatment with $\mathrm{H}_{2}$ antagonists and antibiotics and gastric surgery as risk factors for salmonella infection. BMF 1994;308: 176 .

11 Doe WF. Immunodeficiency and the gastrointestinal tract. Clin Gastroenterol 1983;12:839-53.

12 Madsen KL, Yanchar NL, Sigalet DL, et al. FK 506 increases permeability in rat intestine by inhibiting mitochondrial function. Gastroenterology 1995; 109:107-14.

13 Mainous M, Dazhong X, Qi L, et al. Oral TPN induced bacterial translocation and impaired immune defenses are reversed by refeeding. Surgery tion and impaired

14 Stringer MD, Puntis JWL. Short bowel syndrome. Arch Dis Child 1995;73: $170-3$.

15 Weisdorf SA, Salati JA, Longsdorf NKC, et al. Graft versus host disease of the intestine: a protein loosing enteropathy characterized by fecal alpha 1 antitrypsin. Gastroenterology 1983;85: 1076-81.

16 Nalesnik MA, Starzl TE. Epstein-Barr virus, infectious mononucleosis, and posttransplant lymphoproliferative disorders. Trasplant Sci 1994;4:61-79.

17 Opelz G, Henderson R. Incidence of non Hodgkin lymphoma in kidney and heart transplant recipients. Lancet 1993;342:1514-6.

18 Shulman HM, Fisher LB, Schoch HG, et al. Veno-occlusive disease after marrow transplantation: histological correlates of clinical signs and symptoms. Hepatology 1994;19:1171-81.

19 Green ES, Parker NE, Gellert AR, et al. Campylobacter infection mimicking Crohn's disease in an immunodeficient patient. BMf 1984;289:159-60.

20 Cox GJ, Matsui SM, Lo RS, et al. Etiology and outcome of diarrhea after marrow transplantation: a prospective study. Gastroenterology 1994;107: 1398-1407. 
21 Cello JP, Grendell JH, Bausk P, et al. Effect of octreotide on refractory AIDS associated diarrhea. A prospective, multicenter clinical trial. Ann Intern Med 1991;115:705-10

22 Donaldson SS, Jundt S, Ricour C, et al. Radiation enteritis in children. Cancer 1975;35:1167-78.

23 Kaur S, Cooper G, Fakult S, et al. Incidence and outcome of overt gastrointestinal bleeding in patients undergoing bone marrow transplantation. Dig Dis Sci 1996;41:598-603.

24 Benoit G, Moukarzel M, Verdelli G, et al. Gastrointestinal complications in renal transplantation. Transplant Int 1993;6:45-9.

25 Ianco G, Carroccio A, Cavatgio F, et al. Steatocrit test: normal range and physiological variations in infants. F Pediatr Gastroenterol Nutr 1990;11:537 .

26 Appleton AL, Sviland L, Pearson ADJ, et al. The need for endoscopic biopsy in diagnosis of upper gastrointestinal graft versus host disease. 7 Pediatr Gastroenterol Nutr 1993;16:183-5.
27 Haron E, Feld R, Tuffnell P, et al. Hepatic candidiasis: an increasing problem in immunocompromised patients. Am F Med 1987;83:17-26.

28 Ascher NL, Ahrenholtz RL Simmons RL et al. Indium 111 autologous tagged leukocytes in the diagnosis of intraperitoneal sepsis. Arch Surg 1979;114:386-92.

29 Pamilli G, Laffaroli RV, Capuarno G, et al. Changes in intestinal permeability to lactulose induced by cytotoxic chemotherapy. Cancer Treat Rep 1982; 66:1435-6.

30 Losonsky GA, Johnson JP, Winkelstein JA, et al. Oral administration of human serum immunoglobulin in immunodeficient patients with viral gastroenteritis. A pharmacokinetic and functional analysis. F Clin Invest 1985; 76:2362-7.

31 Balisteri WF. Bile acid therapy in pediatric hepatobiliary disease: the role of ursodeoxycholic acid. F Pediatr Gastroenterol Nutr 1997;24:573-89.

32 Tasaki T, Ohto H, Abe R. Prevention of post transfusion graft versus host disease. Fukushima f Med Sci 1993;39:109-11. 